\title{
Association Between Anion Gap and Mortality in Critically III Patients with Cardiogenic Shock
}

\author{
Tingting Zhang' \\ Jie Wang (D) ${ }^{2}$ \\ Xiangyang $\mathrm{Li}^{1}$ \\ 'Department of Clinical Laboratory, The \\ Second Affiliated Hospital and Yuying \\ Children's Hospital of Wenzhou Medical \\ University, Wenzhou, Zhejiang, 325000, \\ People's Republic of China; ${ }^{2}$ Department \\ of Cardiology, The Second Affiliated \\ Hospital and Yuying Children's Hospital, \\ Wenzhou Medical University, Wenzhou, \\ 325000, Zhejiang, People's Republic of \\ China
}

Correspondence: Xiangyang Li Department of Clinical Laboratory, The Second Affiliated Hospital and Yuying Children's Hospital of Wenzhou Medical University, Wenzhou, 325000, Zhejiang,

People's Republic of China

$\mathrm{Tel} / \mathrm{Fax}+86-577-88002019$

Email lxywzhealth@aliyun.com
Background: No epidemiological study has determined the association between the anion gap (AG) and all-cause mortality in critically ill patients with cardiogenic shock (CS). This study was conducted to clarify the relationship between the AG and mortality in CS.

Methods: We extracted clinical data from the public database, MIMIC-III V1.4, by using a generalized additive model to identify the nonlinear relationship between the AG and the 30-day mortality in 1248 intensive care unit patients. Cox proportional hazard models were used to assess the association between the AG and the 30-day, 90-day, and 365-day mortality in CS.

Results: The AG and 30-day all-cause mortality showed a nonlinear relationship, indicated by a J-shaped curve. In the multivariate analysis, after adjusting for potential confounders, a high AG was associated with an increased risk of 30-day, 90-day, and 365-day all-cause mortality in patients with CS compared with patients who had low AG (hazard ratio [95\% confidence interval] 1.62 [1.14-2.30]; 1.35 [1.04-1.84]; and 1.38 [1.03-1.84], respectively). Similar results were shown in Model I (adjusted for age, sex and ethnicity) and in Model II (fully adjusting for age, ethnicity, sex, acute kidney injury stage, CHF, renal disease, stroke, malignancy, respiratory failure, pneumonia, sodium, potassium, chloride, BUN, PT, WBC, $\mathrm{pH}$, creatinine, albumin, glucose, bicarbonate, vasopressor use, diastolic blood pressure, respiration rate, temperature, the Elixhauser Comorbidity Index, SOFA score and SAPSII score).

Conclusion: The relationship between the AG and 30-day all-cause mortality followed a J-shaped curve. Higher AG was associated with an increased risk of 30-day, 90-day, and 365-day all-cause mortality in critically ill patients with CS.

Keywords: anion gap, mortality, cardiogenic shock, MIMIC-III, cohort study, Cox proportional hazard regression

\section{Introduction}

Cardiogenic shock (CS) is a clinical condition that is characterized by systemic hypotension and hypoperfusion due to insufficient cardiac output that eventually leads to multiorgan failure; CS carries risks of high morbidity and high mortality. ${ }^{1}$ Acute myocardial infarction (MI) is the commonest cause of CS, and acute ischemic CS has a more than $50 \%$ in-hospital mortality rate. ${ }^{2}$ Moreover, CS can occur as an acute manifestation of non-ischemic cardiomyopathy or as a result of severe decompensation in chronic cardiomyopathy, although these are the less frequent causes. ${ }^{3}$ Given the poor prognosis of CS in critically ill patients, researchers have sought a simple and reliable prognostic biomarker. ${ }^{4-6}$ However, these biomarkers have not been widely applied in clinical practice. 
The serum anion gap (AG) is caused by the excessive production of organic acid anions and/or a proportional decrease in anion excretion. ${ }^{7}$ The $\mathrm{AG}$ is a mathematically derived parameter that can potentially be applied in the diagnosis of various metabolic acidosis. ${ }^{8}$ Previous studies have demonstrated that the AG is associated with mortality in several diseases, including sepsis, ${ }^{9}$ aortic aneurysm, ${ }^{10}$ coronary artery disease (CAD) ${ }^{11}$ acute myocardial infarction (AMI), ${ }^{12}$ chronic kidney disease $(\mathrm{CKD}),{ }^{13}$ and the intensive care unit (ICU). ${ }^{14,15}$ Furthermore, a study has reported the prognostic value of the $A G$ in the patient of CS requiring extracorporeal membrane oxygenation (ECMO) support. ${ }^{16}$ But no epidemiological study has explored the association between the AG and the all-cause mortality in all critically ill patients with CS. Therefore, in this study, we analyzed the data from a public clinical database with an aim to clarify the relationship between the AG and the mortality in CS.

\section{Methods}

\section{Data Source}

We used data from the Multiparameter Intelligent Monitoring in Intensive Care III version 1.4 (MIMIC-III v1.4), a public clinical critical care database. ${ }^{17}$ The database contains comprehensive, time-stamped information for more than 60,000 ICU patients (medical, surgical, coronary care and neonatal) admitted to Beth Israel Deaconess Medical Center (Boston, MA, USA) from June 1st 2001 to October 31st 2012 (single center). The data include patient demographics; dates of hospital admission, discharge, and death (in or out of the hospital); International Classification of Diseases (ICD-9) codes; physiological indices; medications; laboratory tests; chemistry; hematology; imaging; fluid balance; and others. This study was approved by the Institutional Review Boards of Beth Israel Deaconess Medical Center (Boston, MA) and the Massachusetts Institute of Technology (Cambridge, MA); a waiver of informed consent was granted.

\section{Population-Selection Criteria}

The inclusion criteria were age $\geq 18$ years; CS, diagnosed using the ICD-9 code at the first ICU admission; and hospitalization in the ICU for more than 2 days. The exclusion criteria were: (1) missing data on the AG at the time of ICU admission, and (2) re-admission to the ICU.

\section{Data Extraction}

Structured Query Language (SQL) with PostgreSQL (version 9.6) was used to extract data on clinical parameters, including demographics, vital signs, laboratory tests, comorbidities, scoring systems, etc., within the first 24 $\mathrm{h}$ after the ICU admission. The comorbidities that were extracted included CAD, congestive heart failure (CHF), atrial fibrillation (AFIB), stroke, renal disease, liver disease, pneumonia, malignancy, respiratory failure, and acute respiratory distress syndrome (ARDS). The laboratory tests included the levels of AG, albumin, bicarbonate, bilirubin, creatinine, chloride, glucose, hematocrit, hemoglobin, platelet, sodium, potassium, lactate, blood urea nitrogen (BUN), white blood cell (WBC), prothrombin time (PT), activated partial thromboplastin time (APTT), and the international normalized ratio (INR).

Furthermore, the Sequential Organ Failure Assessment (SOFA) score $^{18}$ and the Simplified Acute Physiology Scores II (SAPSII) ${ }^{19}$ were obtained. In addition, we extracted data on age, sex, ethnicity, systolic blood pressure (SBP), diastolic blood pressure (DBP), mean blood pressure (MBP), heart rate, respiratory rate, temperature, and SPO2, renal replacement therapy (RRT), vasopressor use, and the length of stay in the ICU as well as in the hospital. Information on the survival status was obtained from the Social Security Death Index records. The endpoints of our study were the 30-day, 90-day, and 365-day all-cause mortality from the date of ICU admission.

\section{Statistical Analysis}

Continuous variables are presented as the mean \pm standard deviation (SD) or the median and interquartile range (IQR). Categorical data are summarized as frequencies or percentages. We used the chi-square, one-way ANOVA, and Kruskal-Wallis $H$-tests to determine significant differences between the means and proportions among the study groups. We used a generalized additive model to identify the non-linear relationship between the AG and the 30-day mortality. In addition, we used Cox proportional hazards models to assess the association between the $A G$ and the 30-day, 90-day, and 365-day mortality in CS, and presented the results from the unadjusted, minimally adjusted, and fully adjusted analyses. The results are presented as hazard ratios (HR) with 95\% confidence intervals (CI). Basic characteristics of population (age, sex and ethnicity) were chosen as minimally adjusted confounders. Fully adjusted confounders were be selected based on a more 
than $10 \%$ change in the effect estimate. ${ }^{20}$ Subgroup analysis of the associations between the AG and the 30-day all-cause mortality was performed using stratified linear regression models. The modifications and interactions of the subgroups were analyzed using likelihood ratio tests. All probability values were two-sided, and values less than 0.05 were considered statistically significant. $\mathrm{R}$ (http:// www.R-project.org) and EmpowerStats (http://www. empowerstats.cn/, X\&Y solutions, Inc, Boston, MA) were used for all statistical analyses.

\section{Results}

\section{Characteristics of Participants}

A total of 1248 ICU patients met the inclusion criteria. The baseline characteristics of the participants are summarized in Table 1; participants were grouped into quartiles by the AG. The participants of this study were generally older, mostly male, White patients. In the study subgroup with a higher AG (Q4), the patients were more likely to have hypotension, and to report a comorbidity of renal disease, with significantly higher values for the heart rate, creatinine, glucose, hematocrit, potassium, lactate, BUN, WBC, PT, APTT, INR, SOFA, SAPSII, renal replacement therapy, vasopressor use, and mortality.

\section{Relationship Between the AG and Mortality}

We found that the relationship between the AG and the 30-day all-cause mortality was non-linear, as shown by a J-shaped curve (Figure 1). To further evaluate the associations between the AG and the 30-day, 90-day, and 365-day all-cause mortality in patients with CS, a Cox proportional hazards regression model was used. We stratified the AG by quartiles and have shown the adjusted models in Table 2. In Model I (adjusted for age, sex, and ethnicity), a higher AG was associated with an increased risk of all-cause mortality. After fully adjusting for age, ethnicity, sex, acute kidney injury stage, CHF, renal disease, stroke, malignancy, respiratory failure, pneumonia, sodium, potassium, chloride, BUN, PT, WBC, $\mathrm{pH}$, creatinine, albumin, glucose, bicarbonate, vasopressor use, diastolic blood pressure, respiration rate, temperature, the Elixhauser Comorbidity Index, SOFA score, and SAPSII score in Model II, the high AG remained a significant predictor of 30-day, 90-day, and 365-day all-cause mortality compared with low AG (HR [95\% CI], 1.62 [1.14$2.30] ; 1.35$ [1.04-1.84]; and 1.38 [1.03-1.84], respectively). Furthermore, for the sensitivity analysis, we considered the $\mathrm{AG}$ as a categorical variable, and observed the same trends ( $p$ for trends: $<0.0001$, 0.0010 , and 0.0015 for the 30-day, 90-day, and 365day all-cause mortality, respectively).

\section{Subgroup Analyses}

The results of the subgroup analysis of the associations between the AG and the 30-day all-cause mortality is shown in Table 3. The test for interactions was not statistically significant in most of the strata. Significant interactions were observed for ethnicity, CAD, bilirubin, hematocrit, hemoglobin, chloride, respiratory rate, and RRT $(P<0.05)$. Among these strata, patients with a higher AG exhibited significantly higher mortality, especially with regard to chloride $\geq 102 \mathrm{mmol} / \mathrm{L}$ and a respiratory rate $\geq 20$ beats/minute. A similar trend was observed in White patients and those with CAD.

\section{Discussion}

Our study demonstrated a J-shaped, nonlinear relationship between the AG and the 30-day all-cause mortality. After adjusting for covariates, a higher AG was associated with an increased risk of 30-day, 90-day, and 365-day all-cause mortality in critically ill patients with CS. Furthermore, after adjusting for additional confounding factors, a higher AG remained a significant predictor of all-cause mortality. High AG is associated with higher mortality in the multivariate model and the overall trend in the quartiles was statistically significant are match to the J-shape curve. It shows that the mortality of CS patients increases with the increase of AG level, and it is more obvious when the AG level is higher.

The AG is an applied mathematically derived parameter that has been used for more than 50 years and is the simplest method for the evaluation of patients based on the acid-base status, which is calculated as the difference between the measured serum cation and anion concentrations. ${ }^{7}$ Traditionally, the AG is one of the most commonly used biomarkers, and this parameter is routinely determined in all patients who are admitted to the ICU. Calculating the AG of critically ill patients is considered a sensitive and specific tool for predicting the prognosis or mortality risk. ${ }^{21,22}$ 
Table I Baseline Characteristics of the Study Patients According to Anion Gap (N=1248)

\begin{tabular}{|c|c|c|c|c|c|}
\hline \multirow[t]{2}{*}{ Characteristic } & \multicolumn{4}{|c|}{ Anion Gap, $\mathrm{mmol} / \mathrm{L}$} & \multirow[t]{2}{*}{$P$ value } \\
\hline & QI $(<12)$ & $Q 2(\geq 12-<14)$ & Q3 $(\geq 14-<17)$ & $\mathbf{Q 4}(\geq 17)$ & \\
\hline Age, years & $71.4 \pm 12.7$ & $70.4 \pm 13.1$ & $69.7 \pm 14.4$ & $72.1 \pm 14.4$ & 0.050 \\
\hline Gender, n (\%) & & & & & 0.751 \\
\hline Female & $90(41.9)$ & II 4 (39.3) & $159(39.8)$ & $148(43.0)$ & \\
\hline Male & $125(58.1)$ & $176(60.7)$ & $240(60.2)$ & $196(57.0)$ & \\
\hline Ethnicity, n (\%) & & & & & 0.664 \\
\hline White & $|5|(70.2)$ & $203(70.0)$ & $275(68.9)$ & $226(65.7)$ & \\
\hline Black & $17(7.9)$ & $17(5.9)$ & $28(7.0)$ & $21(6.1)$ & \\
\hline Other & $47(21.9)$ & $70(24.1)$ & $96(24.1)$ & $97(28.2)$ & \\
\hline $\mathrm{SBP}, \mathrm{mmHg}$ & $106.1 \pm 11.7$ & $104.5 \pm 12.3$ & $104.6 \pm 13.4$ & $100.3 \pm 14.9$ & $<0.001$ \\
\hline $\mathrm{DBP}, \mathrm{mmHg}$ & $56.7 \pm 9.3$ & $58.0 \pm 10.2$ & $57.9 \pm 9.9$ & $55.7 \pm 10.6$ & $<0.001$ \\
\hline MBP, $\mathrm{mmHg}$ & $73.2 \pm 7.9$ & $74.2 \pm 9.4$ & $74.2 \pm 9.8$ & $70.7 \pm 11.2$ & 0.029 \\
\hline Heart rate, beats/minute & $88.1 \pm 15.6$ & $88.0 \pm 16.9$ & $90.5 \pm 17.4$ & $90.4 \pm 17.6$ & 0.073 \\
\hline Respiratory rate, beats/minute & $19.1 \pm 3.8$ & $19.7 \pm 4.1$ & $20.4 \pm 4.1$ & $20.9 \pm 4.3$ & $<0.001$ \\
\hline Temperature, ${ }^{\circ} \mathrm{C}$ & $36.7 \pm 0.7$ & $36.8 \pm 0.8$ & $36.8 \pm 0.9$ & $36.5 \pm 1.0$ & $<0.001$ \\
\hline $\mathrm{SPO} 2, \%$ & $97.1 \pm 3.8$ & $97.1 \pm 2.5$ & $96.7 \pm 3.2$ & $94.7 \pm 7.1$ & $<0.001$ \\
\hline \multicolumn{6}{|l|}{ Comorbidities, n (\%) } \\
\hline Coronary artery disease & $134(62.3)$ & $172(59.3)$ & $230(57.6)$ & $169(49.1)$ & 0.008 \\
\hline Congestive heart failure & $96(44.7)$ & $119(41.0)$ & $169(42.4)$ & $143(4 \mid .6)$ & 0.861 \\
\hline Atrial fibrillation & $97(45.1)$ & $149(51.4)$ & $174(43.6)$ & $168(48.8)$ & 0.184 \\
\hline Stroke & $14(6.5)$ & $16(5.5)$ & $19(4.8)$ & $14(4.1)$ & 0.604 \\
\hline Renal disease & $4 \mid(19.1)$ & $46(15.9)$ & $81(20.3)$ & $108(31.4)$ & $<0.001$ \\
\hline Liver disease & $7(3.3)$ & II (3.8) & $10(2.5)$ & $10(2.9)$ & 0.802 \\
\hline Pneumonia & $76(35.3)$ & $92(31.7)$ & $136(34.1)$ & $99(28.8)$ & 0.322 \\
\hline Malignancy & $29(13.5)$ & $34(11.7)$ & $37(9.3)$ & $37(10.8)$ & 0.431 \\
\hline Respiratory failure & $108(50.2)$ & $143(49.3)$ & $209(52.4)$ & $153(44.5)$ & 0.189 \\
\hline ARDS & $3(1.4)$ & $5(1.7)$ & II (2.8) & $4(1.2)$ & 0.394 \\
\hline \multicolumn{6}{|l|}{ Laboratory parameters } \\
\hline Anion gap, mmol/L & $10.1 \pm 1.2$ & $12.6 \pm 0.5$ & $14.9 \pm 0.8$ & $19.9 \pm 3.6$ & $<0.001$ \\
\hline Albumin, $g / d L$ & $3.0 \pm 0.7$ & $3.0 \pm 0.7$ & $3.1 \pm 0.6$ & $3.2 \pm 0.6$ & 0.009 \\
\hline Bicarbonate, mg/dL & $21.9 \pm 5.2$ & $20.8 \pm 4.9$ & $19.8 \pm 4.4$ & $16.8 \pm 4.9$ & $<0.001$ \\
\hline Bilirubin, $\mathrm{mg} / \mathrm{dL}$ & $1.4 \pm 2.6$ & $1.1 \pm 1.2$ & $0.9 \pm 1.8$ & $1.4 \pm 2.9$ & $<0.001$ \\
\hline Creatinine, $\mathrm{mEq} / \mathrm{L}$ & $\mathrm{I} . \mathrm{I} \pm 0.6$ & $1.2 \pm 0.7$ & $1.6 \pm 1.0$ & $2.8 \pm 2.1$ & $<0.001$ \\
\hline Chloride, $\mathrm{mmol} / \mathrm{L}$ & $102.9 \pm 6.6$ & $102.6 \pm 5.4$ & $101.2 \pm 6.1$ & $99.3 \pm 6.3$ & $<0.001$ \\
\hline Glucose, mg/dL & $105.8 \pm 32.9$ & $118.2 \pm 42.6$ & $127.8 \pm 49.1$ & $133.9 \pm 70.0$ & $<0.001$ \\
\hline Hematocrit, \% & $28.1 \pm 6.2$ & $29.4 \pm 6.1$ & $30.9 \pm 6.5$ & $30.3 \pm 6.7$ & $<0.001$ \\
\hline Hemoglobin, g/dL & $9.4 \pm 2.0$ & $10.0 \pm 2.2$ & $10.4 \pm 2.3$ & $10.0 \pm 2.2$ & $<0.001$ \\
\hline Platelet, $10^{9} / \mathrm{L}$ & $173.3 \pm 82.9$ & $188.7 \pm 104.8$ & $214.2 \pm 107.1$ & $208.7 \pm 113.1$ & $<0.001$ \\
\hline Sodium, $\mathrm{mmol} / \mathrm{L}$ & $135.8 \pm 4.6$ & $135.6 \pm 4.6$ & $\mid 35.1 \pm 5.3$ & $134.4 \pm 5.2$ & 0.007 \\
\hline Potassium, $\mathrm{mmol} / \mathrm{L}$ & $3.6 \pm 0.5$ & $3.7 \pm 0.5$ & $3.8 \pm 0.6$ & $4.0 \pm 0.7$ & $<0.001$ \\
\hline Lactate, $\mathrm{mmol} / \mathrm{L}$ & $1.7 \pm 1.2$ & $2.0 \pm 1.4$ & $2.1 \pm 1.3$ & $3.6 \pm 2.8$ & $<0.001$ \\
\hline BUN, mg/dL & $24.0 \pm 13.8$ & $25.6 \pm 14.0$ & $34.6 \pm 21.4$ & $48.8 \pm 28.1$ & $<0.001$ \\
\hline WBC, $10^{9} / \mathrm{L}$ & $10.6 \pm 11.0$ & $10.7 \pm 4.7$ & $12.0 \pm 5.2$ & $12.8 \pm 6.6$ & $<0.001$ \\
\hline PT, second & $15.5 \pm 4.9$ & $15.8 \pm 7.6$ & $15.7 \pm 5.4$ & $18.3 \pm 9.4$ & $<0.001$ \\
\hline APTT, second & $36.0 \pm 16.9$ & $37.7 \pm 18.7$ & $38.4 \pm 19.1$ & $44.7 \pm 27.5$ & $<0.001$ \\
\hline INR & $1.4 \pm 0.6$ & $1.5 \pm 1.0$ & $1.5 \pm 0.6$ & $2.0 \pm 1.8$ & $<0.001$ \\
\hline
\end{tabular}

(Continued) 
Table I (Continued).

\begin{tabular}{|c|c|c|c|c|c|}
\hline \multirow[t]{2}{*}{ Characteristic } & \multicolumn{4}{|c|}{ Anion Gap, $\mathrm{mmol} / \mathrm{L}$} & \multirow[t]{2}{*}{$P$ value } \\
\hline & QI $(<12)$ & $Q 2(\geq 12-<14)$ & Q3 $(\geq 14-<17)$ & $Q 4(\geq 17)$ & \\
\hline \multicolumn{6}{|l|}{ Scoring systems } \\
\hline SOFA & $6.5 \pm 3.4$ & $6.2 \pm 3.6$ & $6.5 \pm 3.4$ & $8.7 \pm 3.6$ & $<0.001$ \\
\hline SAPSII & $43.8 \pm 12.4$ & $43.5 \pm 14.9$ & $45.4 \pm 14.3$ & $55.2 \pm 15.1$ & $<0.001$ \\
\hline AKI stage, n (\%) & & & & & $<0.001$ \\
\hline Stage 1 & $4 \mid(19.1)$ & $34(11.7)$ & $48(12.1)$ & $44(12.8)$ & \\
\hline Stage 2 & $53(24.7)$ & $69(23.8)$ & $76(19.1)$ & $34(9.9)$ & \\
\hline Stage 3 & $113(52.6)$ & $162(55.9)$ & $253(63.6)$ & $242(70.3)$ & \\
\hline Renal replacement therapy, n (\%) & $23(10.7)$ & $27(9.3)$ & $59(14.8)$ & $94(27.3)$ & $<0.001$ \\
\hline Vasopressor use, n (\%) & $167(77.7)$ & $235(81.0)$ & $321(80.5)$ & $293(85.2)$ & 0.140 \\
\hline ICU LOS, day & $8.3 \pm 9.2$ & $7.7 \pm 7.9$ & $8.4 \pm 8.8$ & $7.3 \pm 12.2$ & $<0.001$ \\
\hline Hospital LOS, day & $15.5 \pm 12.9$ & $15.4 \pm 16.7$ & $15.3 \pm 13.6$ & $12.6 \pm 17.0$ & $<0.001$ \\
\hline 30-day mortality, n (\%) & $65(30.2)$ & $82(28.3)$ & $143(35.8)$ & $223(64.8)$ & $<0.001$ \\
\hline 90-day mortality, n (\%) & $95(44.2)$ & $106(36.6)$ & $175(43.9)$ & $242(70.3)$ & $<0.001$ \\
\hline 365-day mortality, n (\%) & $106(49.3)$ & $138(47.6)$ & $198(49.6)$ & $265(77.0)$ & $<0.001$ \\
\hline
\end{tabular}

Abbreviations: SBP, systolic blood pressure; DBP, diastolic blood pressure; MBP, mean blood pressure; ARDS, acute respiratory distress syndrome; BUN, blood urea nitrogen; WBC, white blood cell; PT, prothrombin time; APTT, activated partial thromboplastin time; INR, international normalized ratio; SOFA, Sequential Organ Failure Assessment; SAPSII, Simplified Acute Physiology Score II; AKI, acute kidney injury; ICU, intensive care unit; LOS, length of stay.

Previous studies reported that an increase in the AG may have prognostic significance in several diseases. ${ }^{9-}$ 11,23 In this study, a U-shaped relationship was

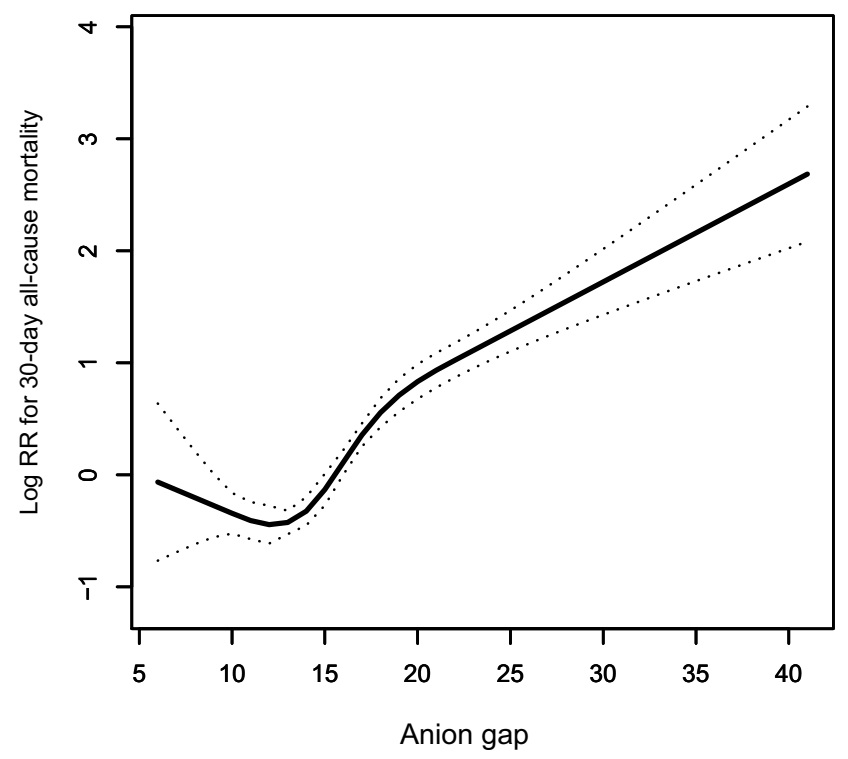

Figure I Association between anion gap and 30-day all-cause mortality. A threshold, nonlinear association between anion gap and 30-day all-cause mortality was found in a generalized additive mode. Solid rad line represents the smooth curve fit between variables. Imaginary lines represent the $95 \%$ of confidence interval from the fit. observed with regard to AG and the all-cause mortality, and the AG was identified as a significant predictor of poor prognosis in CS patients after adjusting for relevant confounding factors.

Due to the insufficient cardiac output, CS constitutes a clinical syndrome of systemic hypotension and hypoperfusion that causes multiorgan failure, which manifests as oliguria, lactic acidosis, hyperpigmentation, and clammy limbs. ${ }^{24}$ An elevated serum AG is usually caused by the excessive production of organic acid anions and/or a concomitant decrease in anion excretion, ${ }^{7}$ wherein the lactic acid level and ketoanions are important factors. ${ }^{25} \mathrm{~A}$ possible mechanism is that the metabolic rate of patients with CS is significantly increased, with consequent sympathetic activation, accelerated glycolysis, and increased lactate levels; patients with heart failure and acute coronary syndrome have significantly elevated levels of blood ketone bodies. ${ }^{26-28}$ Furthermore, CS patients often have concomitant impairment of glomerular filtration function, which results in the retention of non-chlorine anions due to the accumulation of acidic substances. ${ }^{13}$ All of these data strongly suggest that higher AG might be associated with the prognosis of patients with CS; 
Table 2 Relationship Between Anion Gap and All-Cause Mortality in Different Models

\begin{tabular}{|c|c|c|c|c|c|c|}
\hline \multirow[t]{2}{*}{ Variable } & \multicolumn{2}{|c|}{ Crude Model } & \multicolumn{2}{|c|}{ Model I } & \multicolumn{2}{|c|}{ Model II } \\
\hline & HR (95\% Cls) & $P$ value & HR (95\% Cls) & $P$ value & HR (95\% Cls) & $P$ value \\
\hline \multicolumn{7}{|l|}{ 30-day all-cause mortality } \\
\hline Anion gap, mmol/L & $1.12(1.11,1.14)$ & $<0.0001$ & $1.13(1.11,1.15)$ & $<0.0001$ & $1.07(1.04,1.10)$ & $<0.0001$ \\
\hline $\begin{array}{l}\text { Anion gap (Quartile), mmol/L } \\
\quad<12 \\
\geq 12,<14 \\
\geq 14,<17 \\
\geq 17 \\
P \text { for trend }\end{array}$ & $\begin{array}{l}\text { I.0(ref) } \\
0.97(0.70,1.34) \\
1.25(0.94,1.68) \\
3.13(2.37,4.13) \\
<0.000 \text { I }\end{array}$ & $\begin{array}{l}0.8524 \\
0.1296 \\
<0.0001\end{array}$ & $\begin{array}{l}\text { I.0(ref) } \\
\text { I.03 (0.74, I.42) } \\
\text { I.32 (0.99, I.77) } \\
3.18(2.41,4.20) \\
<0.000 \mathrm{I}\end{array}$ & $\begin{array}{l}0.8652 \\
0.0612 \\
<0.0001\end{array}$ & $\begin{array}{l}\text { I.0(ref) } \\
0.82(0.58, I .15) \\
0.96(0.70,1.32) \\
1.62(1.14,2.30) \\
<0.0001\end{array}$ & $\begin{array}{l}0.2496 \\
0.7923 \\
0.0068\end{array}$ \\
\hline \multicolumn{7}{|l|}{ 90-day all-cause mortality } \\
\hline Anion gap, mmol/L & $1.12(1.10,1.13)$ & $<0.0001$ & $1.12(1.11,1.14)$ & $<0.0001$ & $1.06(1.03,1.09)$ & $<0.0001$ \\
\hline $\begin{array}{l}\text { Anion gap (Quartile), mmol/L } \\
\quad<12 \\
\geq 12,<14 \\
\geq 14,<17 \\
\geq 17 \\
P \text { for trend }\end{array}$ & $\begin{array}{l}\mathrm{I} .0 \text { (ref) } \\
0.84(0.64, \mathrm{I} . \mathrm{II}) \\
1.05(0.82, \mathrm{I} .35) \\
2.43(\mathrm{I} .92,3.09) \\
<0.000 \mathrm{I}\end{array}$ & $\begin{array}{l}0.2206 \\
0.7062 \\
<0.0001\end{array}$ & $\begin{array}{l}1.0(\text { ref }) \\
0.90(0.68,1.18) \\
1.12(0.87,1.44) \\
2.51(1.97,3.18) \\
<0.0001\end{array}$ & $\begin{array}{l}0.4409 \\
0.3741 \\
<0.0001\end{array}$ & $\begin{array}{l}1.0(\text { ref) } \\
0.74(0.55,1.02) \\
0.80(0.61,1.05) \\
1.35(1.04,1.84) \\
0.0010\end{array}$ & $\begin{array}{l}0.0813 \\
0.1125 \\
0.0429\end{array}$ \\
\hline \multicolumn{7}{|l|}{ 365-day all-cause mortality } \\
\hline Anion gap, $\mathrm{mmol} / \mathrm{L}$ & $1.11(1.10,1.13)$ & $<0.0001$ & $1.12(1.10,1.14)$ & $<0.0001$ & $1.05(1.03,1.08)$ & 0.0001 \\
\hline $\begin{array}{l}\text { Anion gap (Quartile), mmol/L } \\
\quad<12 \\
\geq 12,<14 \\
\geq 14,<17 \\
\geq 17 \\
P \text { for trend }\end{array}$ & $\begin{array}{l}\text { I.0(ref) } \\
0.97(0.75,1.25) \\
1.06(0.84,1.34) \\
2.47(1.97,3.10) \\
<0.0001\end{array}$ & $\begin{array}{l}0.8116 \\
0.6422 \\
<0.0001\end{array}$ & $\begin{array}{l}\text { I.0(ref) } \\
1.03(0.80,1.33) \\
1.13(0.89,1.43) \\
2.55(2.04,3.20) \\
<0.0001\end{array}$ & $\begin{array}{l}0.8250 \\
0.3045 \\
<0.0001\end{array}$ & $\begin{array}{l}1.0(\text { ref) } \\
0.86(0.66,1.12) \\
0.81(0.63,1.05) \\
1.38(1.03,1.84) \\
0.0015\end{array}$ & $\begin{array}{l}0.2651 \\
0.1129 \\
0.0303\end{array}$ \\
\hline
\end{tabular}

Notes: Models were derived from Cox proportional hazards regression models. Crude model adjust for: none. Adjust I model adjust for: age, ethnicity and gender. Adjust II model adjust for: age, ethnicity, gender, acute kidney injury stage, congestive heart failure, renal disease, stroke, malignancy, respiratory failure, pneumonia, sodium, potassium, chloride, BUN, PT, WBC, PH, creatinine, albumin, glucose, bicarbonate, vasopressor use, diastolic blood pressure, respiration rate, temperature, Elixhauser index, SOFA, SAPSII.

Abbreviations: $\mathrm{HR}$, hazard ratio; $\mathrm{Cl}$, confidence interval.

therefore, the results of this study support the abovementioned hypothesis.

Furthermore, McDonald, C.I. et al had reported the prognostic value of the $\mathrm{AG}$ in the patient of $\mathrm{CS}$ requiring ECMO support. ${ }^{16}$ But our study has explored the association between the $\mathrm{AG}$ and the all-cause mortality in all critically ill patients with CS which mean our study covered a wider population and applied to a wider range of people.

There are a few limitations of our study. First, as this was a retrospective analysis, the analysis is subject to selection bias. Second, the ICD-9 code for CS was used for diagnosis which may lead to bias. Third, we extracted the AG data for patients only based on the test upon their admission to the ICU and did not determine the trends of the changes in the AG, which may influence the reliability of the results. Fourth, as information on prognostic factors, such as cardiac troponin levels, was not available for some patients in the database, we were unable to calibrate all of the relevant confounders. Finally, this was an observational study and, therefore, we could not confirm the potential mechanism of action whereby a higher AG was related to the severity and prognosis of CS.

\section{Conclusions}

The relationship between the AG and 30-day all-cause mortality followed a J-shaped curve. Higher AG was 
Table 3 Subgroup Analysis of the Associations Between Anion Gap and 30-Day All-Cause Mortality

\begin{tabular}{|c|c|c|c|c|}
\hline Characteristic & $\mathbf{N}$ & HR (95\% Cl) & $P$ value & $\begin{array}{l}P \text { for } \\
\text { Interaction }\end{array}$ \\
\hline Age, years & & & & 0.2008 \\
\hline$<72.9$ & 621 & $1.14(1.11,1.17)$ & $<0.0001$ & \\
\hline$\geq 72.9$ & 627 & $1.12(1.10,1.15)$ & $<0.0001$ & \\
\hline Gender & & & & 0.6247 \\
\hline Female & 511 & $1.12(1.09,1.14)$ & $<0.0001$ & \\
\hline Male & 737 & $1.13(1.11,1.15)$ & $<0.0001$ & \\
\hline Ethnicity & & & & 0.0041 \\
\hline White & 855 & $1.16(1.13,1.19)$ & $<0.0001$ & \\
\hline Black & 83 & $1.07(1.00,1.14)$ & 0.0491 & \\
\hline Other & 310 & $1.11(1.08,1.14)$ & $<0.0001$ & \\
\hline $\mathrm{CHF}$ & & & & 0.7634 \\
\hline No & 721 & $1.13(1.10,1.15)$ & $<0.0001$ & \\
\hline Yes & 527 & $1.14(1.11,1.18)$ & $<0.0001$ & \\
\hline CAD & & & & $<0.0001$ \\
\hline No & 543 & $1.10(1.07,1.12)$ & $<0.0001$ & \\
\hline Yes & 705 & $1.19(1.15,1.22)$ & $<0.0001$ & \\
\hline AFIB & & & & 0.4855 \\
\hline No & 660 & $1.13(1.11,1.16)$ & $<0.0001$ & \\
\hline Yes & 588 & $1.13(1.10,1.16)$ & $<0.0001$ & \\
\hline Renal disease & & & & 0.0383 \\
\hline No & 972 & $1.15(1.12,1.18)$ & $<0.0001$ & \\
\hline Yes & 276 & $1.11(1.08,1.15)$ & $<0.0001$ & \\
\hline Liver disease & & & & 0.6737 \\
\hline No & 1210 & $1.13(1.11,1.15)$ & $<0.0001$ & \\
\hline Yes & 38 & $1.10(0.95,1.27)$ & 0.2030 & \\
\hline Stroke & & & & 0.4105 \\
\hline No & 1185 & $1.13(1.11,1.15)$ & $<0.0001$ & \\
\hline Yes & 63 & $1.25(1.04,1.49)$ & 0.0166 & \\
\hline Pneumonia & & & & 0.0698 \\
\hline No & 845 & $1.14(1.12,1.16)$ & $<0.0001$ & \\
\hline Yes & 403 & $1.11(1.06,1.15)$ & $<0.0001$ & \\
\hline Respiratory failure & & & & 0.0517 \\
\hline No & 635 & $1.15(1.12,1.17)$ & $<0.0001$ & \\
\hline Yes & 613 & $1.12(1.09,1.15)$ & $<0.0001$ & \\
\hline ARDS & & & & 0.3866 \\
\hline No & 1225 & $1.14(1.12,1.16)$ & $<0.0001$ & \\
\hline Yes & 23 & $1.04(0.90,1.20)$ & 0.5706 & \\
\hline Malignancy & & & & 0.9078 \\
\hline No & 1111 & $1.14(1.12,1.16)$ & $<0.0001$ & \\
\hline Yes & 137 & $1.16(1.10,1.22)$ & $<0.0001$ & \\
\hline Albumin, g/dL & & & & 0.0812 \\
\hline$<3.1$ & 315 & $1.10(1.07,1.13)$ & $<0.0001$ & \\
\hline$\geq 3.1$ & 384 & $1.16(1.11,1.21)$ & $<0.0001$ & \\
\hline
\end{tabular}

(Continued)
Table 3 (Continued).

\begin{tabular}{|c|c|c|c|c|}
\hline Characteristic & $\mathbf{N}$ & HR (95\% Cl) & $P$ value & $\begin{array}{l}P \text { for } \\
\text { Interaction }\end{array}$ \\
\hline Bicarbonate, $\mathrm{mg} / \mathrm{dL}$ & & & & 0.4811 \\
\hline$<20$ & 597 & $1.11(1.09,1.14)$ & $<0.0001$ & \\
\hline$\geq 20$ & 651 & $1.14(1.09,1.19)$ & $<0.0001$ & \\
\hline Bilirubin, $\mathrm{mg} / \mathrm{dL}$ & & & & 0.0259 \\
\hline$<0.7$ & 418 & $1.14(1.09,1.19)$ & $<0.0001$ & \\
\hline$\geq 0.7$ & $44 I$ & $1.13(1.10,1.15)$ & $<0.0001$ & \\
\hline Sodium, mmol/L & & & & 0.1491 \\
\hline$<135$ & 502 & $1.12(1.09,1.15)$ & $<0.0001$ & \\
\hline$\geq 135$ & 746 & $1.15(1.12,1.17)$ & $<0.0001$ & \\
\hline Potassium, mmol/L & & & & 0.1660 \\
\hline$<3.7$ & 562 & $1.15(1.11,1.20)$ & $<0.0001$ & \\
\hline$\geq 3.7$ & 686 & $1.13(1.11,1.15)$ & $<0.0001$ & \\
\hline Lactate, $\mathrm{mmol} / \mathrm{L}$ & & & & 0.5146 \\
\hline$<1.8$ & 465 & $1.10(1.05,1.16)$ & 0.0001 & \\
\hline$\geq 1.8$ & 494 & $1.10(1.08,1.13)$ & $<0.0001$ & \\
\hline BUN, $\mathrm{mg} / \mathrm{dL}$ & & & & 0.1278 \\
\hline$<27$ & 591 & $1.14(1.10,1.18)$ & $<0.0001$ & \\
\hline$\geq 27$ & 657 & $1.12(1.10,1.15)$ & $<0.0001$ & \\
\hline PT, second & & & & 0.0816 \\
\hline$<14.5$ & 604 & $1.15(1.10,1.20)$ & $<0.0001$ & \\
\hline$\geq 14.5$ & 606 & $1.12(1.10,1.14)$ & $<0.0001$ & \\
\hline INR & & & & 0.0708 \\
\hline$<1.3$ & 498 & $1.17(1.11,1.23)$ & $<0.0001$ & \\
\hline$\geq 1.3$ & 713 & $1.12(1.10,1.14)$ & $<0.0001$ & \\
\hline APTT, second & & & & 0.7576 \\
\hline$<32.9$ & 610 & $1.12(1.07,1.16)$ & $<0.0001$ & \\
\hline$\geq 32.9$ & 606 & $1.13(1.11,1.15)$ & $<0.0001$ & \\
\hline WBC, $10^{9} / \mathrm{L}$ & & & & 0.6960 \\
\hline$<10.8$ & 624 & $1.12(1.09,1.15)$ & $<0.0001$ & \\
\hline$\geq 10.8$ & 622 & $1.15(1.12,1.18)$ & $<0.0001$ & \\
\hline Platelet, $10^{9} / \mathrm{L}$ & & & & 0.1366 \\
\hline$<184$ & 620 & $1.12(1.09,1.14)$ & $<0.0001$ & \\
\hline$\geq 184$ & 627 & $1.18(1.14,1.22)$ & $<0.0001$ & \\
\hline Hematocrit, \% & & & & 0.0157 \\
\hline$<29.6$ & 619 & $1.11(1.08,1.13)$ & $<0.0001$ & \\
\hline$\geq 29.6$ & 629 & $1.19(1.15,1.23)$ & $<0.0001$ & \\
\hline Hemoglobin, g/dL & & & & 0.0100 \\
\hline$<9.9$ & 602 & $1.11(1.09,1.14)$ & $<0.0001$ & \\
\hline$\geq 9.9$ & 645 & $1.19(1.15,1.23)$ & $<0.0001$ & \\
\hline Creatinine, $\mathrm{mEq} / \mathrm{L}$ & & & & 0.3452 \\
\hline$<1.3$ & 605 & $1.11(1.06,1.16)$ & $<0.0001$ & \\
\hline$\geq 1.3$ & 643 & $1.13(1.10,1.15)$ & $<0.0001$ & \\
\hline
\end{tabular}

(Continued) 
Table 3 (Continued).

\begin{tabular}{|c|c|c|c|c|}
\hline Characteristic & $\mathbf{N}$ & HR (95\% Cl) & $P$ value & $\begin{array}{l}P \text { for } \\
\text { Interaction }\end{array}$ \\
\hline Glucose, $\mathrm{mg} / \mathrm{dL}$ & & & & 0.1169 \\
\hline$<114$ & 616 & $1.12(1.10,1.15)$ & $<0.0001$ & \\
\hline$\geq 114$ & 632 & $1.15(1.12,1.18)$ & $<0.0001$ & \\
\hline Chloride, mmol/L & & & & 0.0027 \\
\hline$<102$ & 611 & I.II (I.09, I.14) & $<0.0001$ & \\
\hline$\geq 102$ & 637 & $1.17(1.14,1.20)$ & $<0.0001$ & \\
\hline $\mathrm{SBP}, \mathrm{mmHg}$ & & & & 0.4507 \\
\hline$<103$ & 621 & $1.13(1.11,1.15)$ & $<0.0001$ & \\
\hline$\geq 103$ & 621 & $1.13(1.08,1.17)$ & $<0.0001$ & \\
\hline $\mathrm{DBP}, \mathrm{mmHg}$ & & & & 0.0629 \\
\hline$<57$ & 620 & $1.14(1.12,1.17)$ & $<0.0001$ & \\
\hline$\geq 57$ & 622 & $1.12(1.09,1.15)$ & $<0.0001$ & \\
\hline MBP, $\mathrm{mmHg}$ & & & & 0.0626 \\
\hline$<72$ & 619 & $1.14(1.12,1.17)$ & $<0.0001$ & \\
\hline$\geq 72$ & 624 & $1.10(1.07,1.14)$ & $<0.0001$ & \\
\hline $\begin{array}{l}\text { Heart rate, beats/ } \\
\text { minute }\end{array}$ & & & & 0.2923 \\
\hline$<89$ & 621 & 1.14 (I.II, I.17) & $<0.0001$ & \\
\hline$\geq 89$ & 622 & $1.13(1.11,1.16)$ & $<0.0001$ & \\
\hline $\begin{array}{l}\text { Respiratory rate, } \\
\text { beats/minute }\end{array}$ & & & & 0.0195 \\
\hline$<20$ & 617 & $1.12(1.08,1.17)$ & $<0.0001$ & \\
\hline$\geq 20$ & 626 & $1.13(1.10,1.15)$ & $<0.0001$ & \\
\hline Temperature, ${ }^{\circ} \mathrm{C}$ & & & & 0.2451 \\
\hline$<36.7$ & 593 & $1.13(1.10,1.16)$ & $<0.0001$ & \\
\hline$\geq 36.7$ & 599 & $1.16(1.12,1.20)$ & $<0.0001$ & \\
\hline SPO2, \% & & & & 0.4524 \\
\hline$<97$ & 620 & $1.14(1.11,1.16)$ & $<0.0001$ & \\
\hline$\geq 97$ & 620 & $1.13(1.09,1.17)$ & $<0.0001$ & \\
\hline SOFA score & & & & 0.6956 \\
\hline$<7$ & 556 & $1.10(1.05,1.16)$ & 0.0003 & \\
\hline$\geq 7$ & 692 & $1.12(1.10,1.14)$ & $<0.0001$ & \\
\hline SAPSII score & & & & 0.6197 \\
\hline$<46$ & 594 & $1.12(1.06,1.18)$ & $<0.0001$ & \\
\hline$\geq 46$ & 654 & I.II (I.09, I.13) & $<0.0001$ & \\
\hline Vasopressor use & & & & 0.3629 \\
\hline No & 232 & 1.09 (1.01, I.18) & 0.0213 & \\
\hline Yes & 1016 & $1.13(1.11,1.15)$ & $<0.0001$ & \\
\hline RRT & & & & 0.0001 \\
\hline No & 1045 & I.I4 (I.I2, I.I7) & $<0.0001$ & \\
\hline Yes & 203 & $\mathrm{I} .07(\mathrm{I} .03, \mathrm{I} . \mathrm{II})$ & 0.0012 & \\
\hline
\end{tabular}

Abbreviations: $\mathrm{CHF}$, congestive heart failure; CAD, coronary artery disease; AFIB, atrial fibrillation; ARDS, acute respiratory distress syndrome; BUN, blood urea nitrogen; PT, prothrombin time; INR, international normalized ratio; APTT, activated partial thromboplastin time; WBC, white blood cell; SBP, systolic blood pressure; DBP, diastolic blood pressure; MBP, mean blood pressure; SOFA, Sequential Organ Failure Assessment; SAPSII, Simplified Acute Physiology Score II; RRT, renal replacement therapy. associated with an increased risk of 30-day, 90-day, and 365-day all-cause mortality in critically ill patients with CS.

\section{Acknowledgments}

We would like to thank Dr. Su gaofan for editorial help.

\section{Funding}

There is no funding to report.

\section{Disclosure}

The authors report no conflicts of interest in this work.

\section{References}

1. van Diepen S, Katz JN, Albert NM, et al. Contemporary Management of cardiogenic shock: a scientific statement from the American heart association. Circulation. 2017;136(16):e232-e268. doi:10.1161/ CIR.0000000000000525

2. Goldberg RJ, Spencer FA, Gore JM, et al. Thirty-year trends (1975 to 2005 ) in the magnitude of, management of, and hospital death rates associated with cardiogenic shock in patients with acute myocardial infarction: a population-based perspective. Circulation. 2009;119 (9):1211-1219. doi:10.1161/CIRCULATIONAHA.108.814947

3. Gheorghiade M, Pang PS. Acute heart failure syndromes. J Am Coll Cardiol. 2009;53(7):557-573. doi:10.1016/j.jacc.2008.10.041

4. Sleeper LA, Reynolds HR, White HD, et al. A severity scoring system for risk assessment of patients with cardiogenic shock: a report from the SHOCK Trial and Registry. Am Heart $J$. 2010;160(3):443-450. doi:10.1016/j.ahj.2010.06.024

5. Thiele H, Zeymer U, Neumann F-J, et al. Intra-aortic balloon counterpulsation in acute myocardial infarction complicated by cardiogenic shock (IABP-SHOCK II): final 12 month results of a randomised, open-label trial. Lancet. 2013;382(9905):1638-1645. doi:10.1016/S0140-6736(13)61783-3

6. Link A, Pöss J, Rbah R, et al. Circulating angiopoietins and cardiovascular mortality in cardiogenic shock. Eur Heart J. 2013;34 (22):1651-1662. doi:10.1093/eurheartj/ehs487

7. Kraut JA, Madias NE. Serum anion gap: its uses and limitations in clinical medicine. Clin J Am Soc Nephrol. 2007;2(1):162-174. doi:10.2215/CJN.03020906

8. Kraut JA, Nagami GT. The serum anion gap in the evaluation of acid-base disorders: what are its limitations and can its effectiveness be improved? Clin J Am Soc Nephrol. 2013;8(11):2018-2024. doi: $10.2215 / \mathrm{CJN} .04040413$

9. Mohr NM, Vakkalanka JP, Faine BA, et al. Serum anion gap predicts lactate poorly, but may be used to identify sepsis patients at risk for death: a cohort study. J Crit Care. 2018;44:223-228. doi:10.1016/j. jcrc.2017.10.043

10. Chen Q, Chen Q, Li L, et al. Serum anion gap on admission predicts intensive care unit mortality in patients with aortic aneurysm. Exp Ther Med. 2018;16(3):1766-1777.

11. Yang SW, Zhou YJ, Zhao YX, et al. The serum anion gap is associated with disease severity and all-cause mortality in coronary artery disease. J Geriatr Cardiol. 2017;14(6):392-400.

12. Sahu A, Cooper HA, Panza JA. The initial anion gap is a predictor of mortality in acute myocardial infarction. Coron Artery Dis. 2006;17 (5):409-412. doi:10.1097/00019501-200608000-00002

13. Abramowitz MK, Hostetter TH, Melamed ML. The serum anion gap is altered in early kidney disease and associates with mortality. Kidney Int. 2012;82(6):701-709. doi:10.1038/ki.2012.196 
14. Kim MJ, Kim YH, Sol IS, et al. Serum anion gap at admission as a predictor of mortality in the pediatric intensive care unit. Sci Rep. 2017;7(1):1456. doi:10.1038/s41598-017-01681-9

15. Glasmacher SA, Stones W. Anion gap as a prognostic tool for risk stratification in critically ill patients - a systematic review and meta-analysis. BMC Anesthesiol. 2016;16(1):68. doi:10.1186/ s12871-016-0241-y

16. McDonald CI, Brodie D, Schmidt M, et al. Elevated venous to arterial carbon dioxide gap and anion gap are associated with poor outcome in cardiogenic shock requiring extracorporeal membrane oxygenation support. Asaio j. 2021;67(3):263-269. doi:10.1097/ MAT.0000000000001215

17. Johnson AE, Pollard TJ, Shen L, et al. MIMIC-III, a freely accessible critical care database. Sci Data. 2016;3:160035. doi:10.1038/ sdata. 2016.35

18. Allard J. SOFA-an open source framework for medical simulation. Stud Health Technol Inform. 2007;125:13-18.

19. Le Gall JR, Lemeshow S, Saulnier F. A new Simplified Acute Physiology Score (SAPS II) based on a European/North American multicenter study. JAMA. 1993;270(24):2957-2963. doi:10.1001/ jama.1993.03510240069035

20. Agoritsas T, Merglen A, Shah ND, et al. Adjusted Analyses in studies addressing therapy and harm: users' guides to the medical literature. JAMA. 2017;317(7):748-759. doi:10.1001/jama.2016.20029

21. Kaneko M, Hagiwara S, Aoki M, et al. The significance of strong ion gap for predicting return of spontaneous circulation in patients with cardiopulmonary arrest. Open Med. 2017;12(1):33-38. doi:10.1515/ med-2017-0006
22. Ho KM, Lan NSH, Williams TA, et al. A comparison of prognostic significance of strong ion gap (SIG) with other acid-base markers in the critically ill: a cohort study. J Intensive Care. 2016;4(1):43. doi:10.1186/s40560-016-0166-z

23. Taylor EN, Forman JP, Farwell WR. Serum anion gap and blood pressure in the national health and nutrition examination survey. Hypertension. 2007;50(2):320-324. doi:10.1161/ HYPERTENSIONAHA.107.092643

24. Califf RM, Bengtson JR. Cardiogenic shock. N Engl J Med. 1994;330 (24):1724-1730. doi:10.1056/NEJM199406163302406

25. Gabow PA, Kaehny WD, Fennessey PV, et al. Diagnostic importance of an increased serum anion gap. $N$ Engl J Med. 1980;303 (15):854-858. doi:10.1056/NEJM198010093031505

26. Lazzeri C, Valente S, Chiostri M, et al. Clinical significance of lactate in acute cardiac patients. World J Cardiol. 2015;7(8):483-489. doi:10.4330/wjc.v7.i8.483

27. Lommi J, Kupari M, Koskinen P, et al. Blood ketone bodies in congestive heart failure. J Am Coll Cardiol. 1996;28(3):665-672. doi:10.1016/0735-1097(96)00214-8

28. Bedi KC, Snyder NW, Brandimarto J, et al. Evidence for Intramyocardial disruption of lipid metabolism and increased myocardial ketone utilization in advanced human heart failure. Circulation. 2016;133(8):706-716. doi:10.1161/CIRCULATIO NAHA.115.017545
International Journal of General Medicine

\section{Publish your work in this journal}

The International Journal of General Medicine is an international, peer-reviewed open-access journal that focuses on general and internal medicine, pathogenesis, epidemiology, diagnosis, monitoring and treatment protocols. The journal is characterized by the rapid reporting of reviews, original research and clinical studies

\section{Dovepress}

across all disease areas. The manuscript management system is completely online and includes a very quick and fair peer-review system, which is all easy to use. Visit http://www.dovepress.com/ testimonials.php to read real quotes from published authors. 